\title{
RECURRENT ROTATIONAL DEFORMITY OF THE FEMUR AFTER STATIC LOCKING OF INTRAMEDULLARY NAILS
}

\author{
CASE REPORTS \\ CHRISTIAN KRETTEK, THEODORE MICLAU, MICHAEL BLAUTH, RONALD W. LINDSEY, \\ CHRISTIAN DONOW, HARALD TSCHERNE
}

From the Hannover Medical School, Germany

Rotational deformity following intramedullary nailing may cause symptoms and require surgical correction by osteotomy. Reamed, locked intramedullary nailing may be performed, but concern about cortical blood supply and potential pulmonary dysfunction from reaming have led many surgeons to limit this and use smaller diameter nails. Slotted nails are commonly used but are less stiff in torsion than the newer unslotted nails, particularly at the lower diameters.

We report two cased of recurrent femoral rotational deformity after using statically interlocked slotted intramedullary nails to correct existing femoral rotational deformities. These patients show that small diameter statically interlocked femoral nails with diminished bone-nail contact must be stiff enough in rotation to avoid potential recurrence.

J Bone Joint Surg [Br] 1997;79-B:4-8.

Received 13 May 1996; Accepted 15 August 1996

Intramedullary nailing is commonly used for the fixation of fractures of the femoral draft. Rotational deformity after nailing is a well-known complication and can occur during or after operation if locking is not used. ${ }^{1}$ Occasionally, such a deformity can cause symptoms and require correction, ${ }^{1,2}$ often by osteotomy with a reamed, locked intramedullary nail. ${ }^{2}$ There are some concerns, about the adverse effects of

C. Krettek, MD, Professor, Trauma Surgeon

M. Blauth, MD, Privatdozent, Trauma Surgeon

C. Donow, MD, Resident in Trauma Surgery

H. Tscherne, MD, Professor, Head of Trauma Departmen

Hannover Medical School, D 30623 Hannover, Germany.

T. Miclau, MD, Assistant Professor, Orthopaedic Surgeon

Department of Orthopaedic Surgery, San Francisco General Hospital, 1001 Potrero Avenue, Room 3A36, San Francisco, California 94110 , USA.

R. W. Lindsey, MD, Associate Professor, Orthopaedic Surgeon Department of Orthopaedic Surgery, Baylor College of Medicine, 6550 Fannin, Suite 2625, Houston, Texas 77030, USA.

Correspondence should be sent to Dr C. Krettek.

(C)1997 British Editorial Society of Bone and Joint Surgery 0301-620X/97/16910\$2.00 reaming on the cortical blood supply ${ }^{3,4}$ and the potential pulmonary effects. ${ }^{5,6}$ This has prompted a number of surgeons to limit reaming and to use nails of smaller diameter. ${ }^{7}$ Slotted nails are usually inserted, but they are less stiff in torsion than the newer unslotted nails, particularly at smaller diameters ${ }^{7}$ (Table I). The effect of the decreased torsional stiffness of these interlocked nails of small diameter has not been well established, ${ }^{8}$

We report two cases of recurrent femoral rotational deformity after the use of statically interlocked slotted intramedullary nails for the correction of a previous femoral rotational deformity. They illustrate one risk of using slotted femoral intramedullary nails of small diameter.

Table I. Calculated stiffness $\left(\mathrm{Nm}^{2}\right)$ and rotational deformation (degrees) at $4 \mathrm{Nm}$ for slotted and unslotted nails of different diameters. The slot width was $0.7 \mathrm{~mm}$; all other parameters were the same for the calculations of slotted and unslotted nails: profile, round tube; wall thickness, $1.2 \mathrm{~mm}$; working length, $350 \mathrm{~mm}$; shear modulus for stainless steele: $75.19 \mathrm{GPa}$. For comparison, a moment of torque of $4 \mathrm{Nm}$ is usually applied when a $4.5 \mathrm{~mm}$ cortical screw is tightened.'

\begin{tabular}{llllll}
\hline \multirow{2}{*}{$\begin{array}{l}\text { Outside } \\
\text { diameter }(\mathbf{m m})\end{array}$} & \begin{tabular}{l} 
Slotted \\
\cline { 2 - 3 } $\begin{array}{l}\text { Torque } \\
\text { stiffness }\end{array}$
\end{tabular} & $\begin{array}{l}\text { Rotational } \\
\text { deformation }\end{array}$ & $\begin{array}{l}\text { Torque } \\
\text { stiffness }\end{array}$ & $\begin{array}{l}\text { Rotational } \\
\text { deformation }\end{array}$ \\
\hline 11 & 1.3 & 60.8 & 67.7 & 1.2 \\
12 & 1.4 & 55.3 & 90.4 & 0.9 \\
13 & 1.6 & 50.5 & 117.6 & 0.7 \\
14 & 1.7 & 46.4 & 149.9 & 0.5 \\
15 & 1.9 & 43.1 & 187.6 & 0.4 \\
16 & 2.0 & 40.3 & 231.2 & 0.3 \\
17 & 2.1 & 37.5 & 281.1 & 0.3 \\
18 & 2.3 & 35.3 & 337.7 & 0.2 \\
\hline
\end{tabular}

* The calculations are based on equations from Kenedi ${ }^{16}$ and Tencer and Johnson. ${ }^{17}$ The full equations are available on request from the author.

\section{CASE REPORTS}

Case 1. A 20-year-old man sustained a closed midshaft fracture of the left femur in a motor-vehicle accident. At a local hospital a proximally locked reamed $12 \mathrm{~mm}$ AO Universal intramedullary nail (Synthes, Bochum, Switzerland) was inserted. The fracture healed uneventfully but the 


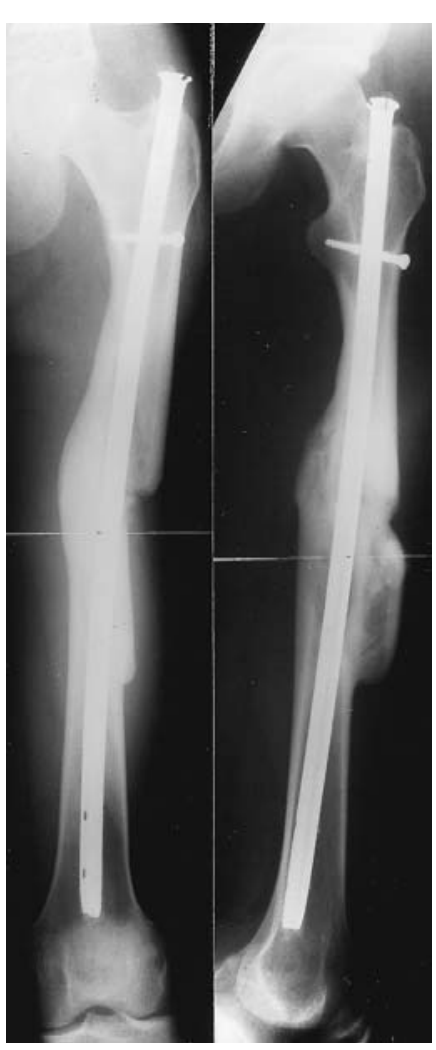

Fig. 1a
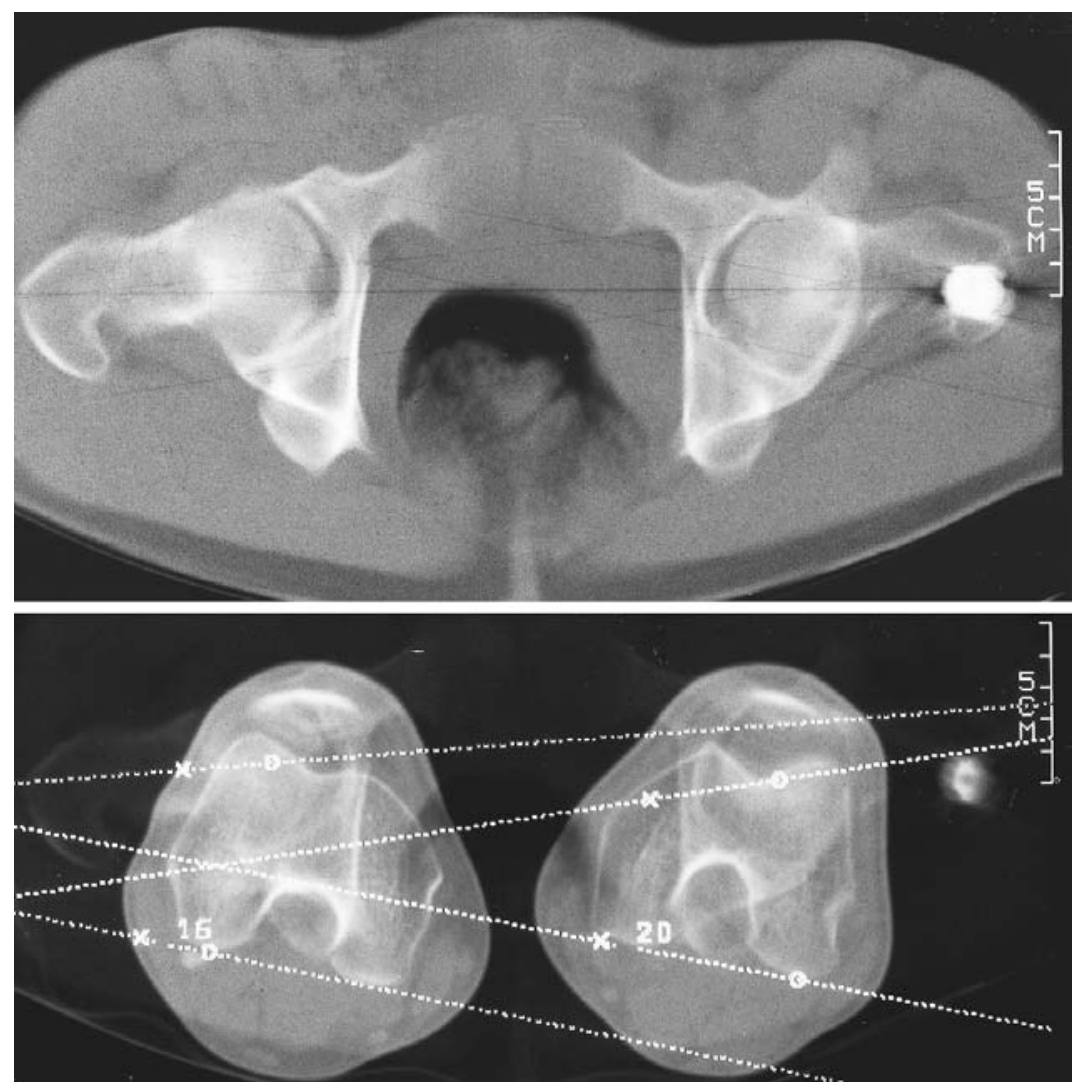

Fig. 1b

Case 1. Figure 1a - Radiographs showing a healed complex transverse fracture of the midshaft of the femur fracture. Internal rotation of the hip is seen with the knee in an anteroposterior projection. Figure $1 \mathrm{~b}-\mathrm{CT}$ shows a left femoral external rotation deformity of $36^{\circ}$.

patient noted an increase in external rotation of his leg. Eleven months after the injury he complained of low-back and hip pain which had prevented his return to sport, and examination confirmed an external rotation deformity of the femur. Plain radiographs showed a healed fracture (Fig. 1a) and CT confirmed a $36^{\circ}$ external rotation deformity of the left femur (Fig. 1b).

We performed a transverse midshaft femoral osteotomy, using a reamed $12 \mathrm{~mm}$ slotted statically interlocked AO Universal nail to stabilise the bone. ${ }^{9}$ Rotational correction was controlled and confirmed by the use of Kirschner wires and a fixed-angle template (Fig. 1c). ${ }^{10}$ Postoperatively, partial weight-bearing $(15 \mathrm{~kg})$ was allowed.

Within the first month after operation, the patient noted a gradual painless return of his rotational deformity. On routine follow-up at six and 11 months, he showed $35^{\circ}$ of rotational malalignment (Fig. 1d). Radiologically, his osteotomy had fully healed, and he was discharged and allowed unrestricted activities.

Over the next two years, he developed hip and anterior knee pain severe enough to stop him playing soccer. Examination at 2.5 years after the correctional osteotomy the clinical external rotational deformity was $35^{\circ}$, plain radiographs showed a healed osteotomy with the nail in place, and CT demonstrated external rotational malalignment of $41^{\circ}$ and $1 \mathrm{~cm}$ of femoral shortening (Fig. 1e). The patient was then treated by an oblique derotational wedge osteotomy stabilised by a plate (Fig. 1f), producing symmetrical hip rotation; CT showed $6.8^{\circ}$ of external rotation (Fig. 1g). The postoperative course was uneventful, and at the 12-week follow-up, the correction was maintained.

Case 2. A 22-year-old man sustained an isolated, closed simple transverse midshaft fracture of the left femur after a motorcycle accident. His fracture was stabilised by a reamed $12 \mathrm{~mm}$ AO Universal intramedullary nail (Synthes, Bochum, Germany) without interlocking screws. The fracture healed uneventfully, but with an external rotational deformity of $30^{\circ}$.

He was allowed to return to full activities, but over the first postoperative year had persistent hip and anterior knee pain. After three years, pain and the appearance of the leg had prevented him from running. Plain radiography showed a well-healed fracture and $\mathrm{CT}$ an external rotational deformity of $32^{\circ}$. A transverse midshaft osteotomy was fixed with a reamed $12 \mathrm{~mm}$ slotted AO Universal nail which was statically locked, ${ }^{9}$ using Kirschner wires and a fixed-angle template to ensure good correction. ${ }^{10}$ Postoperatively, partial weight-bearing $(15 \mathrm{~kg})$ was allowed. 


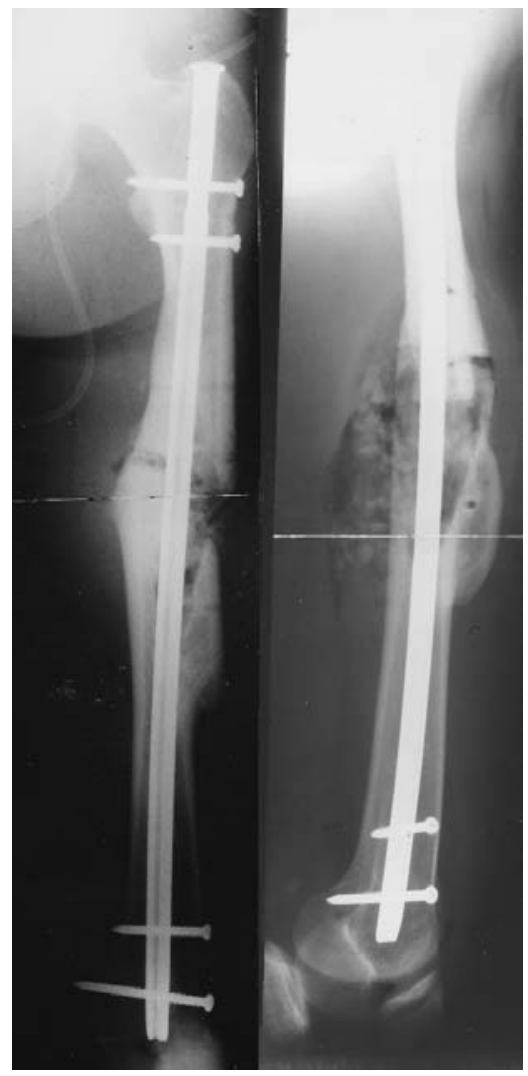

Fig. 1c
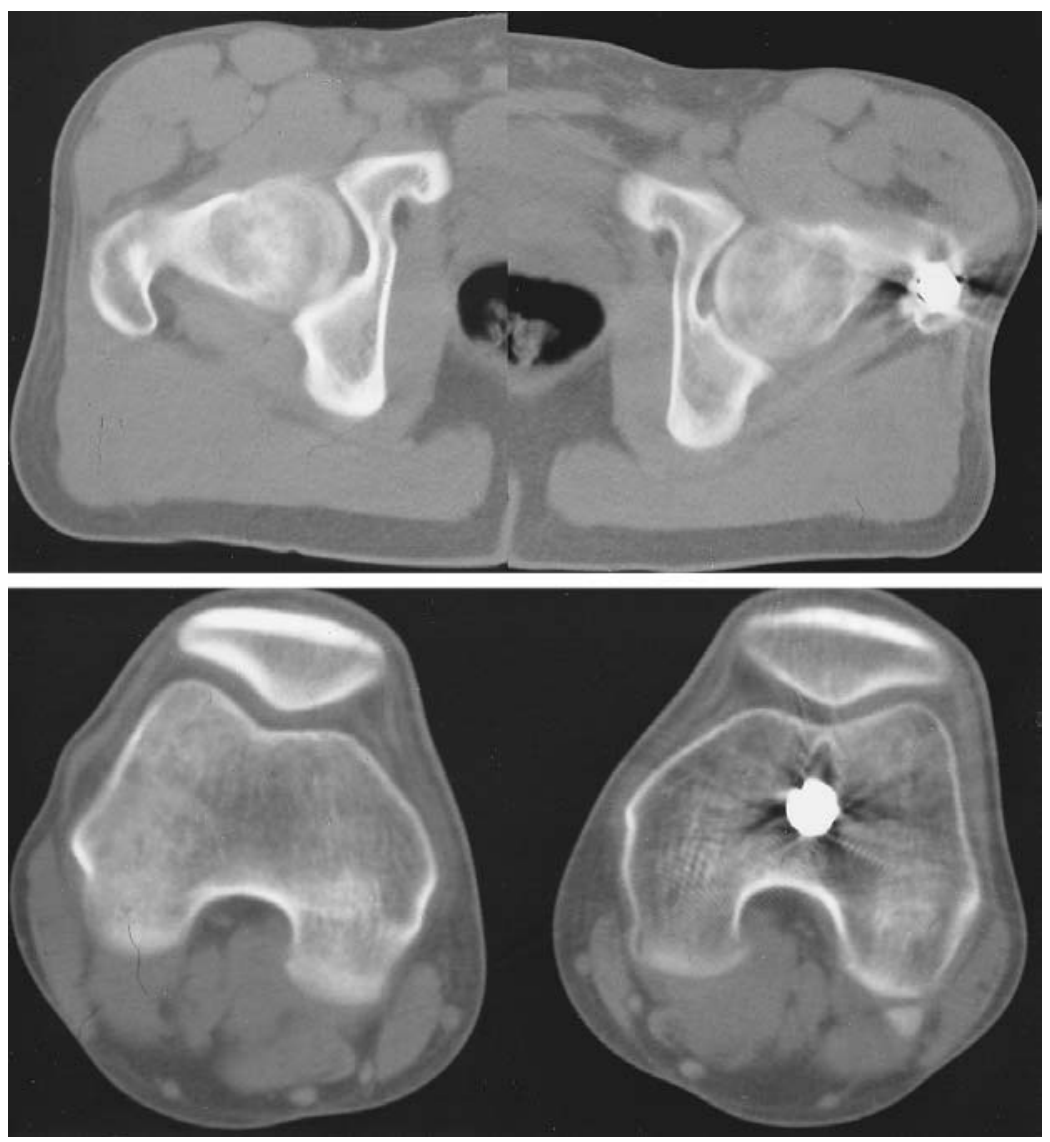

C. KRETTEK, T. MICLAU, M. BLAUTH, ET AL

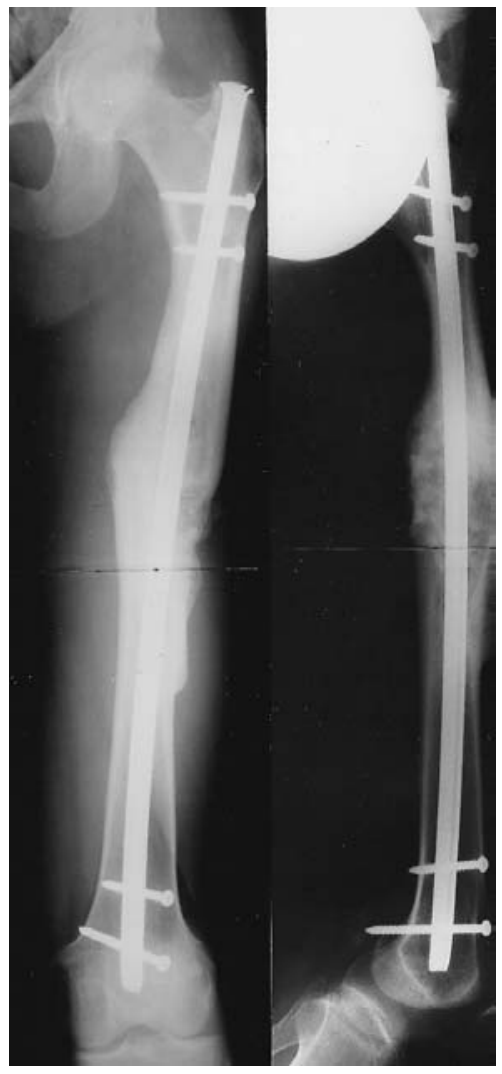

Fig. 1d

\section{Fig. 1e}

Figure 1e - CT showing an external rotation deformity of $41^{\circ}$.

Figure 1c - Radiographs taken immediately after osteotomy and statically locked intramedullary nailing show correction of the rotational deformity. The hip and knee are both in an anteroposterior projection. id - Radiographs one year after correction showing a well-healed osteotomy and the return of rotational deformity. 


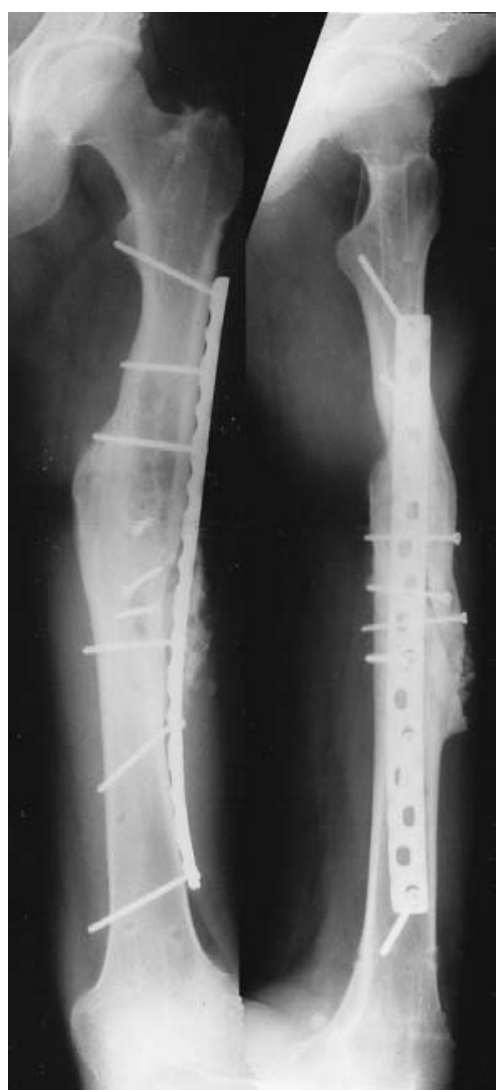

Fig. 1f
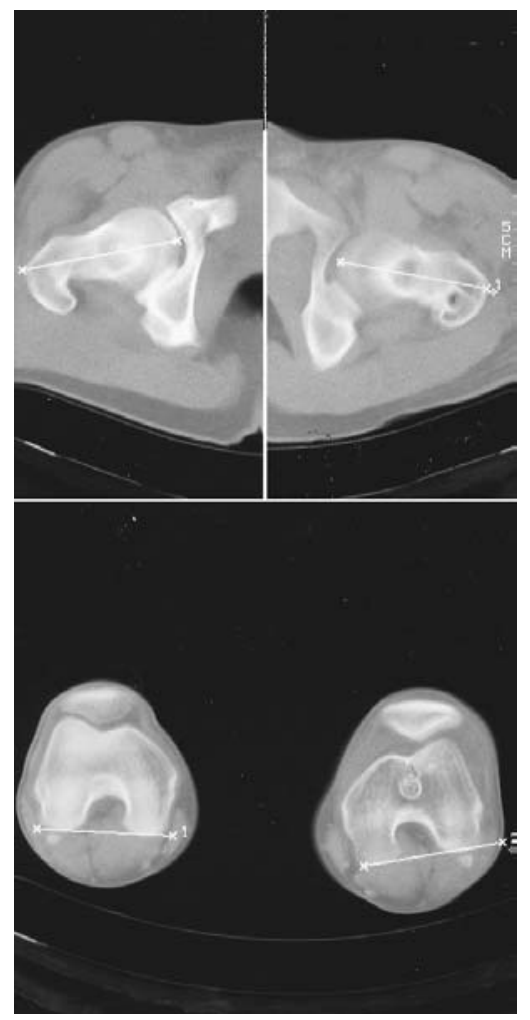

Fig. $1 g$
Figure 1f - Radiographs taken immediately after the second osteotomy show correction of the rotational deformity and osteosynthesis using a plate. Figure $1 \mathrm{~g}-\mathrm{CT}$ after the second osteotomy showing a residual difference in external rotation of only $6.8^{\circ}$.
The osteotomy healed uneventfully, but there was a gradual return of the deformity in the early postoperative period. CT showed external rotational malalignment of $20^{\circ}$, and the patient was still unable to play sports because of hip and knee pain. He was also unhappy with the appearance of his leg.

Six years after the original injury and three years after the previous osteotomy, a transverse osteotomy was stabilised by an unslotted $12 \mathrm{~mm}$ unreamed femoral nail (Synthes,Bochum, Germany), with rotational correction controlled by wires and a template. The postoperative course was uneventful and partial weight-bearing $(15 \mathrm{~kg})$ was allowed from the start. At five months, the patient was painfree and no clinical deformity was detectable.

\section{DISCUSSION}

Post-traumatic femoral rotational deformities are successfully treated by osteotomy and statically locked intramedullary nailing. ${ }^{2}$ Success depends on adequate torsional stiffness of the nail to maintain the corrected alignment. In the past, reamed slotted nails of large diameter have been used which achieve stability by increasing the bone-nail contact area. ${ }^{11}$ Despite the clinical success of reamed intramedullary nailing, limited reaming has become increasingly popular because it causes less devascularisation of cortical bone and fewer pulmonary complications. ${ }^{3,5,6}$ Torsional stiffness decreases with decreasing nail diameter, particularly for slotted nails (Table I) and the effects of this with static locking are uncertain.

Our cases illustrate the risk of using slotted locked nails of small diameter when torsional forces on the implant may be high. To our knowledge, these are the first cases to be reported after statically locked nailing.

Some authors have reported that few clinical problems are caused by torsional femoral deformity, ${ }^{12-14}$ but others have found these to be more common with torsion of over $15^{\circ}{ }^{1}$ The cause of pain and the consequences of femoral rotational deformities are unclear, ${ }^{15}$ but such patients may have considerable hip and anterior knee symptoms.

The torsional stiffness required for the stable fixation of femoral fractures and osteotomies is uncertain, and it seems that statically interlocked femoral nails of small diameter need to be stiff in torsion if they are to control rotation adequately and avoid deformity. We conclude that in such cases, if reaming is to be avoided, a torsionally stiff implant such as an unslotted nail or a plate should be used to stabilise a rotational osteotomy.

The authors gratefully acknowledge the assistance of Jürgen Mannß, engineer in the biomechanics laboratory at the senior author's institution in assembling technical data and performing calculations.

Although none of the authors have received or will receive benefits for personal or professional use from a commercial party related directly or indirectly to the subject of this article, benefits have been or will be received but are directed solely to a research fund, foundation, educational institution, or other non-profit institution with which one or more of the authors is associated. 


\section{REFERENCES}

1. Bråten $\mathbf{M}$, Terjesen $\mathbf{T}$, Rossvoll I. Torsional deformity after intramedullary nailing of femoral shaft fractures: measurement of anteversion angles in 110 patients. J Bone Joint Surg [Br] 1993;75-B: 799-803.

2. Kempf I, Grosse A, Abalo C. Locked intramedullary nailing: its application to femoral and tibial axial rotational, lengthening, and shortening osteotomies. Clin Orthop 1986;212:165-73.

3. Danckwardt-Lilliestrom G, Lorenzi GL, Olerud S. Intramedullary nailing after reaming: an investigation on the healing process in osteotomized rabbit tibias. Acta Orthop Scand Suppl 1970;134:1-78.

4. Kessler SB, Hallfeldt KKJ, Perren SM, Schweiberer L. The effects of reaming and intramedullary nailing on fracture healing. Clin Orthop 1986;212:18-25.

5. Wenda K, Ritter G, Degreif J, Rudigier J. Pathogenesis of pulmonary complications following intramedullary nailing osteosyntheses. Unfallchirurg 1988;91:432-5.

6. Pape H-C, Dwenger A, Regel G, et al. Pulmonary damage after intramedullary femoral nailing in traumatized sheep - is there an effect from different nailing methods? J Trauma 1992;33:574-81.

7. Krettek C, Schulte-Eistrup S, Schandelmaier P, et al. Internal fixation of femoral shaft fractures using the AO unreamed femoral nail (UFN): operative technique and early clinical experience with the standard locking technique. Unfallchirurg 1994;97:549-67.

8. Schandelmaier P, Krettek C, Tscherne H. Biomechanical study of nine different tibia locking nails. J Orthop Trauma 1996;10:37-44.
9. Müller M, Allgöwer M, Schneider R, Willenegger H. Manual of internal fixation. Berlin Heidelberg, etc: Springer, 1990.

10. Baumgartl F, Hohenbleicher R, Seling K. Fehlstellungen und Beinlängenunterschiede nach Schaftbrüchen des Obershenkelknochens. In: Baumgartl F, Kremer K, Schreiber HW, eds. Spezielle Chicurgie für die Praxis. Haltings- und Beweguns apparat-Traumatologie. Band 3/II. Stuttgart: Thieme, 1980:428-9.

11. Olerud S, Stromberg L. Intramedullary reaming and nailing: its early effects on cortical bone vascularization. Orthopedics 1986;9:1204-8.

12. Kempf I, Grosse A, Beck G. Closed locked intramedullary nailing: its application to comminuted fractures of the femur. J Bone Joint Surg [Am] 1985;67-A:709-20.

13. Johnson KD, Greenberg M. Comminuted femoral shaft fractures. Orthop Clin North Am 1987;18:133-47.

14. Wiss DA, Brien WW, Stetson WB. Interlocked nailing for treatment of segmental fractures of the femur. J Bone Joint Surg [Am] 1990; 72-A:724-8.

15. Fabry G, Cheng LX, Molenaers G. Normal and abnormal torsional development in children. Clin Orthop 1995;302:22-6.

16. Kenedi RM. Biomedical engineering. Edinburgh:Blackie \& Son;1980: 54-60.

17. Tencer AF, Johnson KD. Biomechanics in orthopedic trauma. London: Martin Dunitz, 1994. 